\title{
Evaluation of serum free fatty acids in chronic renal failure: evidence from a rare case with undetectable serum free fatty acids and population data
}

Zhen-Xian Liu ${ }^{1 \dagger}$, Qian Hong ${ }^{2,3+}$, Ding-Hui Peng ${ }^{1 \dagger}$, Ying Yang ${ }^{1}$, Wen-Li Yu ${ }^{3}$, Hua Shui ${ }^{3}$, Xin Zhou ${ }^{1}$ and Song-Mei Liu*

\begin{abstract}
Background: Free fatty acid (FFA) accumulation in proximal tubules plays a fundamental role in the progress of kidney disease. Here, we reported a rare case with undetectable serum FFAs and further evaluated the changes of serum FFAs in patients with chronic renal failure (CRF).

Methods: We analyzed the clinical data of a rare case and 574 CRF patients. The mRNA expression of lipoprotein lipase (LPL), hepatic lipase (HL) and fatty acid synthase (FASN) were determined in the rare case and 30 agematched healthy males with $\mathrm{QPCR}$.

Results: This rare case had serious proteinuria, hyperglycemia, lipid disorders and bilateral renal glomerular filtration dysfunction. Compared with healthy males, this case showed a 1.49-fold increase of $L P L$ expression $(P<0.01)$, a 3.38fold reduction of $H L$ expression $(P<0.001)$, and no significant change of FASN expression $(P>0.05)$. In total, $21.6 \%$ of CRF patients showed abnormal FFAs. Biochemical parameters such as blood urea nitrogen (BUN) and creatinine (CREA) significantly differed among groups with low-, normal- or high-level-FFAs. Moreover, serum FFAs was found to be associated with BUN. FFAs decreased in the group with higher BUN (> 17.4 mmol/L) and in the group with lower estimated glomerular filtration rate (eGFR) $\left(<15 \mathrm{~mL} / \mathrm{min} / 1.73 \mathrm{~m}^{2}\right)$.
\end{abstract}

Conclusions: The proteinuria, HL low expression and renal function failure may contribute to the FFA reduction, which might imply that the renal function is severely damaged.

Keywords: Chronic renal failure, Free fatty acids, Proteinuria, Glucose metabolism, Lipid metabolism

\section{Background}

Chronic kidney disease (CKD) represents an everincreasing worldwide health problem [1]. Hypertension, obesity, diabetes and chronic glomerular diseases are risk factors for CKD. Simultaneously, severe CKD could lead to cardiovascular diseases, fracture, anemia, hypertension, and other complications [2, 3]. Chronic renal failure $(\mathrm{CRF})$ would occur if renal function failed to

\footnotetext{
* Correspondence: smliu@whu.edu.cn

†Zhen-Xian Liu, Qian Hong and Ding-Hui Peng contributed equally to this work.

'Department of Clinical Laboratory, Center for Gene Diagnosis and Program of Clinical Laboratory, Zhongnan Hospital, Wuhan University, 169 Donghu Road, Wuhan 430071, Hubei Province, China

Full list of author information is available at the end of the article
}

meet the body needs, requiring replacement therapy (i.e., renal dialysis or kidney transplantation) [4]. The causes of CKD differ by country, race and age. In the United States and the United Kingdom, end-stage kidney disease mainly results from diabetic nephropathy, while primary glomerulonephritis is the leading cause of CRF in China [5].

Free fatty acids (FFAs) are derived from triacylglycerol lipolysis governed by lipoprotein lipase (LPL) [6] and hepatic lipase (HL) [7], or de novo synthesis from acetylCoA, malonyl-CoA and NADPH by fatty acid synthases (FASN) [8]. In proximal tubules, FFAs act as energy sources, membrane components, and precursors of lipid mediators. FFAs could be filtered by glomeruli and 
reabsorbed into the proximal tubules through binding to albumin. In cases of severe proteinuria, hypoxia, or intoxication, FFAs would accumulate in proximal tubules [9]. Excessive FFAs could be esterified with glycerides and deposit in intracellular lipid droplets in the form of triglycerides, which might induce renal damage. In turn, renal dysfunction further aggravates the accumulation of FFAs in proximal tubules. FFA accumulation and overoxidation lead to podocytes structural damages, resulting in glomerulopathy and CRF [10]. Dyslipidemia may affect the kidney directly by lipotoxicity, as well as indirectly through inflammation, oxidative stress, vascular injury, and hormones changes [11]. With the development of CKD, dyslipoproteinemia becomes more pronounced and even could not be substantially improved by dialysis [12].

Abnormal FFA metabolism mediates the development of many diseases, including type 2 diabetes, cardiovascular diseases, and hypertension [13, 14], which are closely related to CRF [2, 3]. However, to date, only a few studies have focused on serum FFAs and CRF, and FFA profile has been only evaluated in patients undergoing dialysis or renal transplantation. Notably, very low serum FFAs are not common in clinical and laboratory observations.

Therefore, it is of great significance to reveal the changes of serum FFAs in the context of renal failure. In this study, we reported a rare case with undetectable serum FFAs and further evaluated the changes of serum FFAs in 574 CRF patients.

\section{Materials and methods \\ Study subjects}

A 43-year-old, male patient with undetectable serum FFAs and 574 CRF patients from May 2017 to August 2018 were recruited in this study. The average age for the 574 CRF patients was $62.9 \pm 0.7$ years and $64.1 \%(n=368)$ were males. For genetic analysis of the case, 30 agematched healthy males $(43.9 \pm 0.7$ years $)$ were also enrolled at Zhongnan Hospital of Wuhan University, China. All patients were diagnosed as CRF according to the Kidney Disease: Improving Global Outcomes (KDIGO) guidelines [15]. Healthy controls were randomly selected from physical examination population who had normal laboratory results, including liver function, kidney function, serum glucose, lipids and electrolytes, regular blood and urine tests. The exclusion criteria were diabetes, cardiovascular diseases or other serious diseases or use of any medication. This study was approved by the Ethics Committee of Zhongnan Hospital of Wuhan University and was performed according to the Declaration of Helsinki.

\section{Clinical biochemical tests}

Biochemical parameters, including serum alanine transaminase (ALT), aspartate aminotransferase (AST), AST/ ALT, total bilirubin (TBIL), direct bilirubin (DBIL), unconjugated bilirubin (UBIL), total protein (TP), albumin, globulin (GLB), gamma-glutamyl transpeptidase (GGT), alkaline phosphatase (ALP), total bile acid (TBA), superoxide dismutase (SOD), glucose (GLU), blood urea nitrogen (BUN), creatinine (CREA), uric acid, carbon dioxide $\left(\mathrm{CO}_{2}\right)$, cystatin $\mathrm{C}$, total cholesterol (TC), triglyceride (TG), high-density lipoprotein cholesterol (HDL-C), low-density lipoprotein cholesterol (LDL-C), apolipoprotein A1 (ApoA1), apolipoprotein B (ApoB), lipoprotein (a) (Lp(a)), FFA, phospholipid (PLIP), $\mathrm{K}^{+}$, $\mathrm{Na}^{+}, \mathrm{Cl}^{-}, \mathrm{Ca}^{2+}, \mathrm{Mg}^{2+}$, phosphate and the 24-h urinary total protein (24h-TP) were assayed using AU5831 automated chemistry analyzer (Beckman, USA). Urine glucose and protein were determined by Urine Dry Chemical Analyzer (AX-4030, Japan).

\section{Calculation of eGFR}

The estimated glomerular filtration rate (eGFR) was calculated according to Chronic Kidney Disease Epidemiology Collaboration creatinine equation: $\mathrm{eGFR}=141 \times$ $\min (\mathrm{Scr} / \kappa, 1)^{\alpha} \times \max (\mathrm{Scr} / \kappa, 1)^{-1.209} \times 0.993^{\text {Age }} \times(1.018$ if female), (Scr, Serum creatinine; unit, $\mathrm{mg} / \mathrm{dL}, 1 \mathrm{mg} /$ $\mathrm{dL}=88.4 \mu \mathrm{mol} / \mathrm{L}$ ). Where $\mathrm{K}=0.7$ for females or 0.9 for males; $\alpha=-0.329$ for females or -0.411 for males [16].

\section{Total RNA extraction}

Total RNA was isolated from fresh white blood cells from the case and 30 healthy males using Trizol Reagent (Invitrogen, USA) according to the manufacturer's protocol.

\section{Gene expression determination}

cDNA was synthesized using a reverse-transcription kit with DNase treatment (TOYOBO, Japan). mRNA expression of $L P L, H L, F A S N$ was evaluated in triplicates using the $\mathrm{iTaq}^{\mathrm{Tm}}$ Universal SYBR GREEN Supermixes (BioRad, USA) on a CFX Connect ${ }^{\text {tm }}$ Real-Time PCR Detection System (BioRad, USA) and double normalization to $\beta$-ACTIN and GAPDH. The primers are listed in Additional file 1: Table S1.

\section{Statistical analysis}

We used SPSS 20.0 to perform all statistical analyses. The flow chart of analysis is shown in Fig. 1. Continuous and normally distributed variables were presented as the mean \pm standard deviation $(\mathrm{M} \pm \mathrm{SD})$, and skewed variables were described by the median (interquartile range, IQR). The nonparametric Mann-Whitney U test was used to compare clinical parameters of CRF patients between different groups. The Spearman's rank correlation test was used for correlation analysis. All statistical tests were two-sided, and $P$-value $<0.05$ was considered statistically significant. 


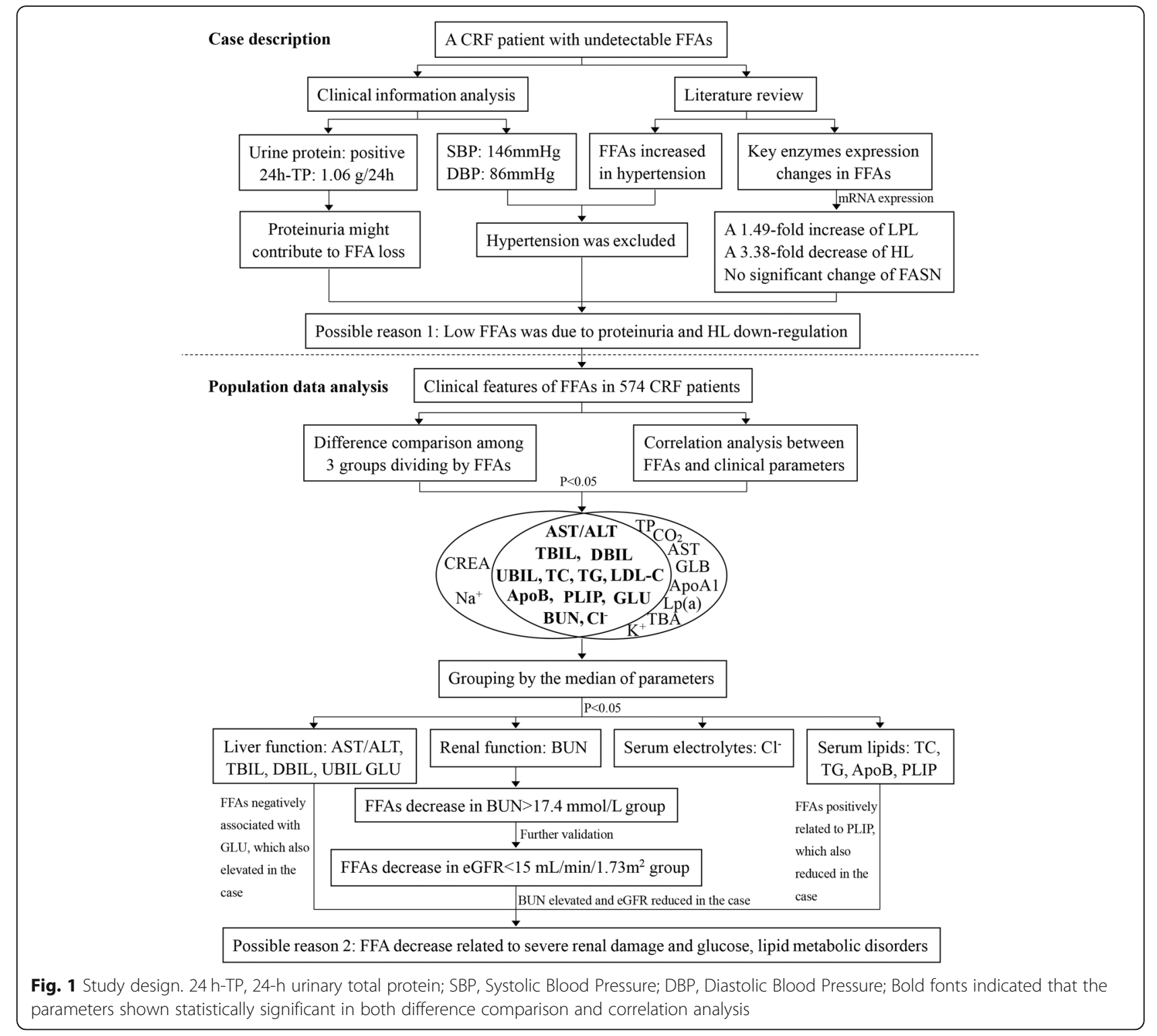

\section{Results}

\section{Case description}

A 43-year-old male was admitted to hospital because of CRF and persistently increased serum creatinine for 7 years, ranging from $451.0-930.8 \mu \mathrm{mol} / \mathrm{L}$ during his hospitalization. He had a history of hypertension for 7 years and took nifedipine controlled-release tablets, and his blood pressure was $146 / 86 \mathrm{mmHg}$ on admission. He had no diabetes, heart disease, hepatitis B virus infection or tuberculosis, and never underwent hemodialysis. For CRF treatment, he also had calcium dobesilate to protect blood vessels and improve circulation, polysaccharideIron(III) complex to fight anemia, sodium bicarbonate to correct acidosis, calcium acetate tablets and vitamin $\mathrm{D}_{3}$ to keep balance of calcium and phosphate metabolism, as well as Hushen Keli, a traditional Chinese patent medicine to improve renal function.

As shown in Table 1, this patient had normal liver function, severely impaired renal function (i.e., increased serum BUN, CREA, Cystatin C, and decreased eGFR), hyperglycemia (GLU, $8.41 \mathrm{mmol} / \mathrm{L}$ ), serum electrolyte disorders (i.e., decreased $\mathrm{Cl}^{-}$and $\mathrm{Ca}^{2+}$, and increased $\mathrm{Mg}^{2+}$, phosphate). Interestingly, the case showed normal serum TC, TG, LDL-C, Lp(a), and decreased HDL-C, PLIP and undetectable FFAs. Additionally, urine glucose and protein were positive, and the $24 \mathrm{~h}$-TP was $1.06 \mathrm{~g} / 24 \mathrm{~h}$ (reference interval: $0-0.15 \mathrm{~g} / 24 \mathrm{~h}$ ). Further renal emission computed tomography (ECT) exam showed: (1) glomerular filtration rate (GFR): bilateral renal GFR was $16.0 \mathrm{~mL} / \mathrm{min}$ (after correction, $16.4 \mathrm{~mL} / \mathrm{min} / 1.73 \mathrm{~m}^{2}$ ), GFR for left and right 
Table 1 Biochemical parameters of the CRF patient with undetectable serum FFAs

\begin{tabular}{|c|c|c|}
\hline Parameter & Result & Reference interval \\
\hline \multicolumn{3}{|l|}{ Liver function } \\
\hline $\mathrm{ALT}(\mathrm{U} / \mathrm{L})$ & 11 & $9-50$ \\
\hline AST (U/L) & 13 & $15-40$ \\
\hline $\mathrm{AST} / \mathrm{ALT}$ & 1.18 & $0.2-2$ \\
\hline TBIL ( $\mu \mathrm{mol} / \mathrm{L})$ & 8.4 & $5-21$ \\
\hline DBIL $(\mu \mathrm{mol} / \mathrm{L})$ & 1.4 & $0-7$ \\
\hline UBIL ( $\mu \mathrm{mol} / \mathrm{L})$ & 7 & $1.5-18$ \\
\hline $\mathrm{TP}(\mathrm{g} / \mathrm{L})$ & 69 & $65-85$ \\
\hline Albumin (g/L) & 44.2 & $40-55$ \\
\hline GLB (g/L) & 24.8 & $20-30$ \\
\hline Albumin/GLB & 1.78 & $1.5-2.5$ \\
\hline GGT(U/L) & 29 & $8-57$ \\
\hline $\operatorname{ALP}(U / L)$ & 55 & $30-120$ \\
\hline TBA $(\mu \mathrm{mol} / \mathrm{L})$ & 3.4 & $0-15$ \\
\hline $\mathrm{SOD}(\mathrm{U} / \mathrm{L})$ & 168.3 & $129-216$ \\
\hline GLU (mmol/L) & 8.41 & $3.9-6.1$ \\
\hline \multicolumn{3}{|l|}{ Renal function } \\
\hline BUN (mmol/L) & 46.4 & $2.8-7.6$ \\
\hline CREA ( $\mu \mathrm{mol} / \mathrm{L})$ & 451 & 64-104 \\
\hline Uric acid $(\mu \mathrm{mol} / \mathrm{L})$ & 356.5 & $208-428$ \\
\hline $\mathrm{CO}_{2}(\mathrm{mmol} / \mathrm{L})$ & 22.2 & $21-29$ \\
\hline Cystatin C(mg/L) & 6.22 & $0-1.2$ \\
\hline eGFR (mL/min/1.73m²) & 12.8 & $>90$ \\
\hline \multicolumn{3}{|l|}{ Serum lipids } \\
\hline $\mathrm{TC}(\mathrm{mmol} / \mathrm{L})$ & 2.54 & $<5.18$ \\
\hline $\mathrm{TG}(\mathrm{mmol} / \mathrm{L})$ & 1.59 & $<1.7$ \\
\hline $\mathrm{HDL}-\mathrm{C}(\mathrm{mmol} / \mathrm{L})$ & 0.74 & $>1.04$ \\
\hline $\mathrm{LDL}-\mathrm{C}(\mathrm{mmol} / \mathrm{L})$ & 1.43 & $<3.63$ \\
\hline LP (a) (mg/L) & 287.1 & $0-300$ \\
\hline PLIP (mmol/L) & 1.61 & $1.9-3.2$ \\
\hline \multicolumn{3}{|l|}{ Serum electrolytes } \\
\hline $\mathrm{K}^{+}(\mathrm{mmol} / \mathrm{L})$ & 3.95 & $3.5-5.3$ \\
\hline $\mathrm{Na}^{+}(\mathrm{mmol} / \mathrm{L})$ & 138 & $137-147$ \\
\hline $\mathrm{Cl}^{-}(\mathrm{mmol} / \mathrm{L})$ & 97.2 & $99-110$ \\
\hline $\mathrm{Ca}^{2+}(\mathrm{mmol} / \mathrm{L})$ & 2.09 & $2.11-2.52$ \\
\hline $\mathrm{Mg}^{2+}(\mathrm{mmol} / \mathrm{L})$ & 1.26 & $0.85-1.15$ \\
\hline Phosphate (mmol/L) & 2.14 & $0.85-1.51$ \\
\hline
\end{tabular}

ALT alanine transaminase, AST aspartate aminotransferase, TBIL total bilirubin, $D B I L$ direct bilirubin, UBIL unconjugated bilirubin, $T P$ total protein, $G L B$ globulin, GGT gamma-glutamyl transpeptidase, ALP alkaline phosphatase, TBA total bile acid, $S O D$ superoxide dismutase, GLU glucose, BUN blood urea nitrogen, CREA creatinine, $\mathrm{CO}_{2}$ carbon dioxide, eGFR estimated glomerular filtration rate, $T C$ total cholesterol, $T G$ triglyceride, $H D L-C$ high-density lipoprotein cholesterol, LDL-C low-density lipoprotein cholesterol, $L p(a)$ lipoprotein (a), PLIP phospholipid. Bold fonts indicated the results are abnormal single-kidney was $9.8 \mathrm{~mL} / \mathrm{min}$ and $6.2 \mathrm{~mL} / \mathrm{min}$, respectively; (2) bilateral renal atrophy; (3) significantly reduction in bilateral renal blood perfusion; (4) severely impaired bilateral renal glomerular filtration function; (5) delayed bilateral renal excretion. The color Doppler ultrasound indicated that no obvious abnormality was observed in radial arteries of both upper limbs, cephalic veins, bilateral carotid or vertebral arteries. Based on the above mentioned results, the patient was diagnosed as CRF (CKD-5) and grade-3 hypertension (extremely high risk) with proteinuria, hyperglycemia and lipid disorders.

\section{Serum FFAs analysis of the case and literature review}

To confirm that the case indeed had undetectable FFAs, we tested his serum FFAs and commercial FFA quality controls for 3 times. The test results showed that quality controls had expected values, and serum FFAs of the patient was only $0.07 \mu \mathrm{mol} / \mathrm{L}$ at the $2^{\text {nd }}$ run detection. Next, to avoid that serum FFA concentration was too high to detect, we tested FFAs with diluted serum, and the results were similar to the undiluted serum. Thus, we attempted to interpret this interesting clinical observation.

In general, FFAs are mainly contained in triglycerideriched lipoproteins or bind to albumin in blood circulation [17]. Albumin-bound FFAs could be filtered through the glomeruli and accumulate in the proximal tubules in the setting of massive proteinuria [9]. Given this case had serious proteinuria (24h-TP, $1.06 \mathrm{~g} / 24 \mathrm{~h}$; urine protein, positive), along with badly impaired bilateral renal GFR, one possible reason for the undetectable FFAs should be FFAs lost with urine protein.

Fig 2a shows the mRNA levels of $L P L, H L$ and FASN. Compared with healthy males, the case had a 1.49-fold increase of $L P L$ expression $(P<0.01)$, a 3.38 -fold reduction of $H L$ expression $(P<0.001)$, and no significant change of $F A S N$ expression $(P>0.05)$. It appeared that the fold-change of $H L$ expression was greater than that of $L P L$. The increased $L P L$ expression might not be able to compensate for the alteration triggered by $H L$ low expression. Thus, the significant down-regulation of $H L$ might be also responsible for the undetectable FFAs.

Hypertension and CRF have found to be the cause and effect in FFA metabolic disorders [2, 14, 18]. FFAs increased in patients with hypertension, suggesting that a higher level of FFAs was an independent risk factor for hypertension $[14,19]$. To our surprise, the case had severe hypertension (grade-3) but with undetectable FFAs. The discrepancy between the case and previous studies might imply that FFA metabolism was complicated in CRF circumstance, and some unknown factors might also have contributed to the undetectable FFAs. 


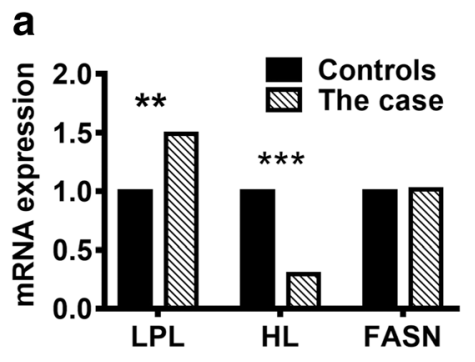

b
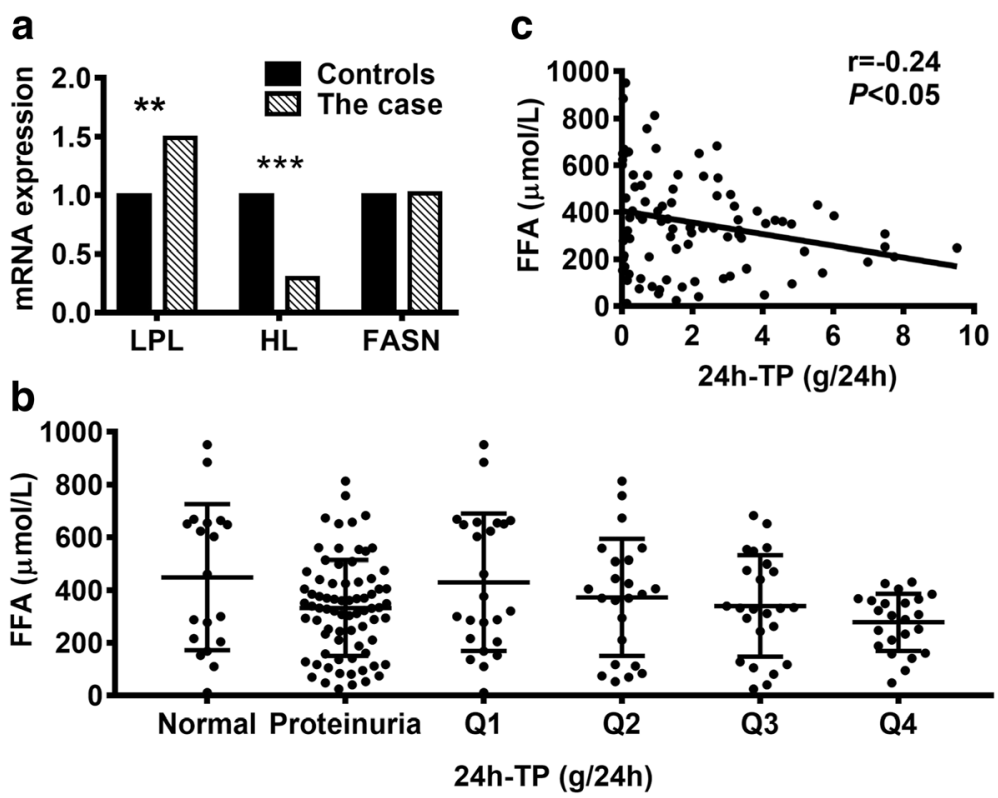

Fig. 2 Analysis of gene expression and the 24-h urinary total proteins. a The mRNA expression of three key enzymes in FFA metabolism. Compared with 30 age-matched healthy males, LPL expression increased 1.49-fold but HL expression decreased 3.38-fold. FASN expression had no significant change. $\mathbf{b}$ Serum FFAs decreased in patients with proteinuria, and showed a decrease tendency with proteinuria aggravating. c Serum FFAs have a negative correlation with $24 \mathrm{~h}-\mathrm{TP} .{ }^{* *} \mathrm{P}<0.01,{ }^{* * *} \mathrm{P}<0.001, \mathrm{Q} 1-4$ indicated the quartile of $24 \mathrm{~h}-\mathrm{TP}$. FFA, free fatty acids; LPL, lipoprotein lipase; HL, hepatic lipase; FASN, fatty acid synthase; $24 \mathrm{~h}-\mathrm{TP}, 24$-h urinary total protein

Taken together, the undetectable FFA in this CRF patient was mainly caused by FFA elimination with urine protein and down-regulation of $H L$.

\section{Population data analysis}

To provide further evidence for the undetectable FFAs in this case and understand FFA changes in CRF patients, we systematically evaluated the alterations of FFAs and clinical parameters in 574 CRF patients. Of them, $13.59 \%$ had decreased FFAs, $8.01 \%$ had increased FFAs, and $78.4 \%$ were normal.

Based on the reference interval of serum FFAs (129$769 \mu \mathrm{mol} / \mathrm{L}$ ), we divided the 574 participants into three groups: FFA-reduced $(<129 \mu \mathrm{mol} / \mathrm{L})$, FFA-normal, and FFA-increased $(>769 \mu \mathrm{mol} / \mathrm{L})$. The average of FFAs in the FFA-reduced group was $82.16 \mu \mathrm{mol} / \mathrm{L}$, and the lowest value was $11.28 \mu \mathrm{mol} / \mathrm{L}$. Next, we examined the difference of laboratory indicators among the three groups with K-independent nonparametric test, including liver function, kidney function, serum lipids and electrolytes (Table 2). No significant difference was found in age $(P=$ $0.053)$ or gender $(P=0.072)$ distribution. Serum AST/ ALT, TBIL, DBIL, UBIL, GLU, BUN, CREA, TC, TG, LDL-C, ApoB, PLIP, $\mathrm{Na}^{+}$and $\mathrm{Cl}^{-}$significantly differed across the three groups. For instance, liver function parameters (i.e., AST/ALT, TBIL, DBIL and UBIL) showed an increasing trend with FFA increasing $(P<0.01)$; serum GLU elevated in both the FFA-reduced group and the

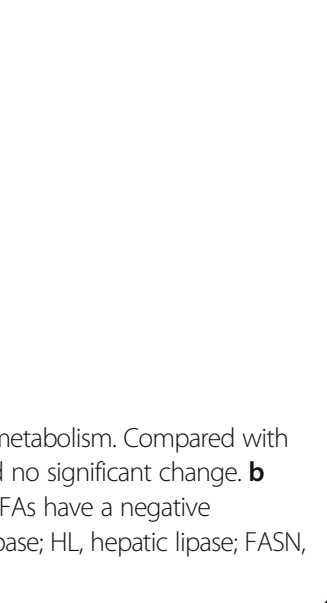

FFA-increased group $(P<0.01)$ when compared to the FFA-normal group. As for renal function indicators, serum BUN in the FFA-reduced group was the highest among the three groups $(P<0.01)$; serum CREA was apparently higher than that in the FFA-normal group $(P<$ $0.01)$. Serum lipids differed across the three groups, except for HDL-C, ApoA1 and $\mathrm{Lp}(\mathrm{a})$. Also, serum $\mathrm{Na}^{+}$and $\mathrm{Cl}^{-}$ showed statistically difference across the three groups. Therefore, our data provided strong evidence that serum FFAs were closely related to the renal function, given the long-standing recommendations for clinical evaluation of renal function with serum BUN and CREA.

In addition to the BUN and CREA, the urine $24 \mathrm{~h}$-TP is another important indicator for renal function. We therefore evaluated serum FFAs in 98 CRF patients who had results of urine $24 \mathrm{~h}-\mathrm{TP}$. Of the 98 patients, $19 \mathrm{pa}-$ tients had normal $24 \mathrm{~h}-\mathrm{TP}(\leq 0.15 \mathrm{~g} / 24 \mathrm{~h})$ and 79 patients showed abnormal increased $24 \mathrm{~h}$-TP. The median of $24 \mathrm{~h}$-TP in this cohort was $1.395 \mathrm{~g} / 24 \mathrm{~h}$ (IQR, 0.2803.115). Consequently, CRF patients with higher urine 24 h-TP were more likely to have lower concentrations of FFAs (Fig. 2b), regardless of grouping by reference interval or the IQR range. More importantly, serum FFAs was found to be negatively associated with urine $24 \mathrm{~h}$-TP $(\mathrm{r}=-0.24, P<0.05$, Fig. 2c).

Furthermore, the Spearman's rank correlation analysis revealed that FFAs had positive correlations with AST, AST/ALT, TBIL, DBIL, UBIL, TP, GLB, $\mathrm{CO}_{2}$, TC, TG, 
Table 2 The differences of clinical parameters across three groups dividing by serum FFAs

\begin{tabular}{|c|c|c|c|c|}
\hline Parameter & FFA-reduced group $(n=78)$ & FFA-normal group $(n=450)$ & FFA-increased group $(n=46)$ & $P$-value \\
\hline Age (year) & $59.3 \pm 1.9$ & $66.0(52.0-76.0)$ & $66.4 \pm 2.2$ & 0.053 \\
\hline \multicolumn{5}{|l|}{ Liver function } \\
\hline $\mathrm{ALT}(\mathrm{U} / \mathrm{L})$ & $16.50(10.00-25.25)$ & $13.00(8.00-20.00)$ & $12.00(7.75-19.25)$ & 0.091 \\
\hline AST (U/L) & $18.00(12.75-25.25)$ & $18.00(14.00-25.00)$ & $22.00(15.5-33.25)$ & 0.078 \\
\hline AST/ALT & $1.17(0.81-1.68)$ & $1.38(1.00-1.75)$ & $1.87(1.00-2.86)$ & 0.001 \\
\hline TBIL ( $\mu \mathrm{mol} / \mathrm{L})$ & $8.15(6.70-10.48)$ & $8.50(7.10-11.30)$ & $10.45(8.50-15.65)$ & $<0.001$ \\
\hline $\mathrm{DBIL}(\mu \mathrm{mol} / \mathrm{L})$ & $1.35(1.00-2.10)$ & $1.50(1.10-2.20)$ & $2.25(1.58-4.15)$ & $<0.001$ \\
\hline UBIL ( $\mu \mathrm{mol} / \mathrm{L})$ & $6.80(5.70-8.53)$ & $7.00(5.83-8.90)$ & $8.05(6.93-12.15)$ & 0.004 \\
\hline $\mathrm{TP}(\mathrm{g} / \mathrm{L})$ & $62.25(59.70-68.60)$ & $64.50(58.90-70.10)$ & $65.58 \pm 1.12$ & 0.169 \\
\hline Albumin $(g / L)$ & $33.94 \pm 0.63$ & $34.80(31.20-39.08)$ & $34.77 \pm 0.90$ & 0.599 \\
\hline GLB (g/L) & $28.81 \pm 0.62$ & $29.20(26.20-33.48)$ & $30.81 \pm 0.85$ & 0.110 \\
\hline Albumin / GLB & 1.14(1.04-1.44) & $1.19(1.00-1.37)$ & $1.18 \pm 0.05$ & 0.791 \\
\hline GGT (U/L) & $24.50(15.00-50.00)$ & $24.00(16.00-43.50)$ & $26.50(17.00-60.00)$ & 0.699 \\
\hline $\operatorname{ALP}(U / L)$ & $83.50(63.50-96.25)$ & $86.00(68.00-108.00)$ & $88.00(63.75-110.00)$ & 0.480 \\
\hline TBA $(\mu \mathrm{mol} / \mathrm{L})$ & $4.35(2.68-6.63)$ & $3.80(2.10-6.50)$ & $3.50(1.78-8.90)$ & 0.350 \\
\hline SOD (U/L) & $135.54 \pm 4.34$ & $127.25 \pm 1.88$ & $136.35 \pm 4.78$ & 0.200 \\
\hline $\mathrm{GLU}(\mathrm{mmol} / \mathrm{L})$ & $6.56(5.25-7.99)$ & $5.05(4.50-6.47)$ & $6.62(4.87-9.37)$ & $<0.001$ \\
\hline \multicolumn{5}{|l|}{ Renal function } \\
\hline BUN (mmol/L) & $21.60(15.10-26.05)$ & 16.75(11.30-23.25) & 15.65(10.55-22.83) & 0.002 \\
\hline CREA $(\mu \mathrm{mol} / \mathrm{L})$ & $688.69 \pm 44.73$ & $479.50(253.60-765.00)$ & $593.93 \pm 61.47$ & 0.005 \\
\hline Uric acid ( $\mu \mathrm{mol} / \mathrm{L})$ & $438.17 \pm 16.93$ & $417.80(333.98-529.58)$ & $443.67 \pm 26.47$ & 0.778 \\
\hline $\mathrm{CO}_{2}(\mathrm{mmol} / \mathrm{L})$ & $21.45 \pm 0.62$ & $22.39 \pm 0.22$ & $22.10 \pm 0.74$ & 0.419 \\
\hline Cystatin C (mg/L) & $4.08(3.17-5.24)$ & $3.78(2.85-5.31)$ & $4.31 \pm 0.36$ & 0.258 \\
\hline $\mathrm{eGFR}\left(\mathrm{mL} / \mathrm{min} / 1.73 \mathrm{~m}^{2}\right)$ & $7.13(4.63-15.01)$ & $8.94(5.36-18.45)$ & $7.10(5.29-22.04)$ & 0.147 \\
\hline \multicolumn{5}{|l|}{ Serum lipids } \\
\hline $\mathrm{TC}(\mathrm{mmol} / \mathrm{L})$ & $3.55 \pm 0.12$ & $3.80(3.20-4.68)$ & $3.70(3.25-4.85)$ & 0.009 \\
\hline $\mathrm{TG}(\mathrm{mmol} / \mathrm{L})$ & $1.56(0.79-1.73)$ & $1.38(1.01-2.04)$ & $1.99(1.39-2.58)$ & $<0.001$ \\
\hline $\mathrm{HDL}-\mathrm{C}(\mathrm{mmol} / \mathrm{L})$ & $0.93 \pm 0.03$ & $0.90(0.72-1.11)$ & $0.84 \pm 0.06$ & 0.088 \\
\hline LDL-C (mmol/L) & $1.86 \pm 0.07$ & $1.97(1.62-2.62)$ & $2.15 \pm 0.12$ & 0.009 \\
\hline ApoA1 (g/L) & $0.99 \pm 0.04$ & $1.00(0.84-1.19)$ & $0.95 \pm 0.08$ & 0.243 \\
\hline ApoB (g/L) & $0.58 \pm 0.03$ & $0.67(0.55-0.80)$ & $0.72 \pm 0.05$ & 0.018 \\
\hline Lp(a) (mg/L) & $171.35(79.48-349.40)$ & $152.35(73.25-316.03)$ & $125.45(63.48-340.75)$ & 0.420 \\
\hline FFA ( $\mu \mathrm{mol} / \mathrm{L})$ & $85.90(55.43-107.07)$ & $348.31(247.31-480.56)$ & $964.61(848.95-1283.06)$ & $<0.001$ \\
\hline PLIP (mmol/L) & $1.96 \pm 0.59$ & $2.06(1.82-2.36)$ & $2.10(1.82-2.67)$ & 0.017 \\
\hline \multicolumn{5}{|l|}{ Serum electrolytes } \\
\hline $\mathrm{K}^{+}(\mathrm{mmol} / \mathrm{L})$ & $4.47 \pm 0.10$ & $4.32(3.90-4.91)$ & $4.25 \pm 0.14$ & 0.178 \\
\hline $\mathrm{Na}^{+}(\mathrm{mmol} / \mathrm{L})$ & $138.20(135.50-141.03)$ & 138.75(136.50-140.80) & 136.75(133.93-139.78) & 0.020 \\
\hline $\mathrm{Cl}^{-}(\mathrm{mmol} / \mathrm{L})$ & 104.20(101.53-109.15) & $104.64 \pm 0.27$ & $100.72 \pm 0.85$ & $<0.001$ \\
\hline $\mathrm{Ca}^{2+}(\mathrm{mmol} / \mathrm{L})$ & $2.08 \pm 0.03$ & $2.17(2.00-2.32)$ & $2.18 \pm 0.05$ & 0.050 \\
\hline $\mathrm{Mg}^{2+}(\mathrm{mmol} / \mathrm{L})$ & $0.96 \pm 0.02$ & $0.95(0.85-1.05)$ & $0.97 \pm 0.04$ & 0.939 \\
\hline Phosphate (mmol/L) & $1.53(1.23-1.96)$ & $1.46(1.15-1.91)$ & $1.56(0.98-1.96)$ & 0.454 \\
\hline
\end{tabular}


Table 3 The correlations between serum FFAs and clinical parameters

\begin{tabular}{|c|c|c|c|}
\hline Parameter & $r$ & $P$-value & Number of Cases \\
\hline \multicolumn{4}{|l|}{ Liver function } \\
\hline ALT & -0.056 & 0.181 & 572 \\
\hline AST & 0.089 & 0.033 & 573 \\
\hline AST/ALT & 0.138 & 0.001 & 568 \\
\hline TBIL & 0.275 & $<0.0001$ & 566 \\
\hline DBIL & 0.230 & $<0.0001$ & 566 \\
\hline UBIL & 0.259 & $<0.0001$ & 568 \\
\hline TP & 0.127 & 0.002 & 569 \\
\hline Albumin & 0.068 & 0.104 & 572 \\
\hline GLB & 0.102 & 0.014 & 572 \\
\hline Albumin/GLB & -0.037 & 0.378 & 572 \\
\hline GGT & 0.046 & 0.269 & 572 \\
\hline ALP & 0.014 & 0.741 & 572 \\
\hline TBA & -0.13 & 0.002 & 572 \\
\hline SOD & 0.038 & 0.445 & 401 \\
\hline GLU & -0.137 & 0.001 & 553 \\
\hline \multicolumn{4}{|l|}{ Renal function } \\
\hline BUN & -0.135 & 0.001 & 568 \\
\hline CREA & -0.069 & 0.097 & 574 \\
\hline Uric acid & 0.052 & 0.212 & 574 \\
\hline $\mathrm{CO} 2$ & 0.102 & 0.015 & 562 \\
\hline Cystatin C & -0.082 & 0.072 & 476 \\
\hline eGFR & 0.042 & 0.317 & 558 \\
\hline \multicolumn{4}{|l|}{ Serum lipids } \\
\hline TC & 0.141 & 0.001 & 574 \\
\hline TG & 0.225 & $<0.0001$ & 574 \\
\hline $\mathrm{HDL}-\mathrm{C}$ & -0.038 & 0.364 & 574 \\
\hline LDL-C & 0.109 & 0.009 & 574 \\
\hline ApoA1 & -0.118 & 0.040 & 301 \\
\hline ApoB & 0.125 & 0.029 & 307 \\
\hline LP (a) & -0.099 & 0.018 & 566 \\
\hline PLIP & 0.175 & 0.0002 & 458 \\
\hline \multicolumn{4}{|l|}{ Serum electrolytes } \\
\hline $\mathrm{K}^{+}$ & -0.115 & 0.006 & 567 \\
\hline $\mathrm{Na}^{+}$ & -0.058 & 0.170 & 571 \\
\hline $\mathrm{Cl}^{-}$ & -0.192 & $<0.0001$ & 569 \\
\hline $\mathrm{Ca}^{2+}$ & 0.081 & 0.053 & 572 \\
\hline $\mathrm{Mg}^{2+}$ & 0.019 & 0.701 & 410 \\
\hline Phosphate & -0.034 & 0.426 & 567 \\
\hline
\end{tabular}

LDL-C, ApoB, PLIP, and negative correlations with TBA, GLU, BUN, ApoA1, Lp(a), $\mathrm{K}^{+}$and $\mathrm{Cl}^{-}$(Table 3).

As shown in Fig. 1, serum AST/ALT, TBIL, DBIL, UBIL, GLU, BUN, TC, TG, LDL-C, ApoB, PLIP, $\mathrm{Cl}^{-}$not only differed significantly (all $P<0.05$ ) across the three groups, but also were significantly associated with serum FFAs. Therefore, we divided the patients into group-1 ( $\leq$ median) and group-2 (> median) on the basis of the median of the above clinical parameters to assess serum FFAs. As illustrated in Fig. 3, the Mann-Whitney U test revealed that serum FFAs were significantly increased in group-2 (AST/ALT, TBIL, DBIL, UBIL, TC, TG, ApoB, PLIP) and in group-1 (GLU, BUN, $\left.\mathrm{Cl}^{-}\right)$. In agreement with that BUN was an important biomarker for renal function evaluation [20], of the 11 indicators, the abnormal rate of BUN was approximately $92.29 \%$, while the rest was less than 50\% (Additional file 1: Table S2). Particularly, the inverse correlation between FFAs and BUN further implied that the lower FFAs reflected poorer renal function.

Additionally, the eGFR was used to evaluate renal function for the vast majority of CKD patients in clinical practice due to convenience and cost-efficiency. The KDIGO guidelines also recommend that CRF patients with $\mathrm{eGFR}<15 \mathrm{~mL} / \mathrm{min} / 1.73 \mathrm{~m}^{2}$ should be classified as CKD-5 stage [15]. We therefore divided patients into two groups by eGFR: group-1 (eGFR < $15 \mathrm{~mL} / \mathrm{min} /$ $\left.1.73 \mathrm{~m}^{2}\right)$ and group-2 (eGFR-2 $\geq 15 \mathrm{~mL} / \mathrm{min} / 1.73 \mathrm{~m}^{2}$ ). Fig. $3 \mathrm{~b}$ demonstrates that FFAs increased in the group-1, indicating inverse correlation between FFAs and kidney function. Consistent with the population data, the case with undetectable FFAs also showed elevated GLU, BUN, and decreased eGFR, PLIP. Collectively, our data demonstrated that FFA reduction was strongly associated with glucose, lipid metabolic disorders, and severe renal damages.

\section{Discussion}

In the current study, we found that a rare case with undetectable FFAs had severe renal dysfunction, hypertension, hyperglycemia, proteinuria and $H L$ down-regulation. Further population data analysis demonstrated that $21.6 \%$ CRF patients had abnormal serum FFAs. Specifically, more CRF patients had decreased FFAs when compared to patients with increased FFAs (13.6\% vs. 8.0\%). FFA reduction could be caused by multiple factors, including loss with proteinuria, hyperglycemia, lipid metabolic disorders, severely impaired renal function and dysregulation of FFA-related enzymes.

In line with a previous report that FFAs showed renoprotective potential, renal transplant recipients with higher plasma FFAs had lower risk of graft failure [21], our population data also suggested that lower serum FFAs indicated worse kidney function in CRF patients. The care with undetectable FFAs had dramatically reduced eGFR $(12 \mathrm{~mL} /$ $\mathrm{min} / 1.73 \mathrm{~m}^{2}$ ), proteinuria, and significantly increased BUN, CREA. By telephone follow-up, we noticed that this patient had been taking hemodialysis owing to out of controlled 


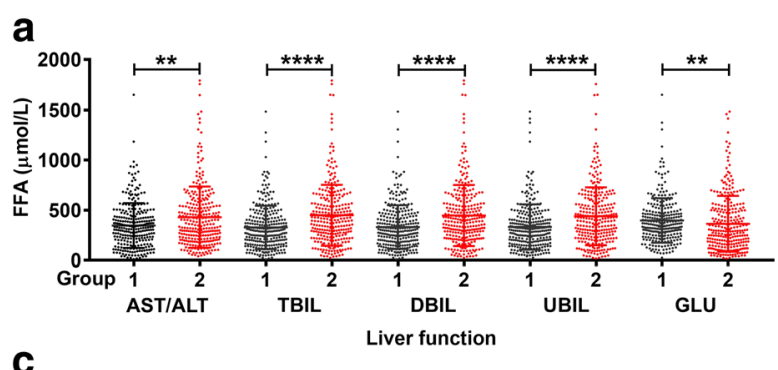

\section{b}
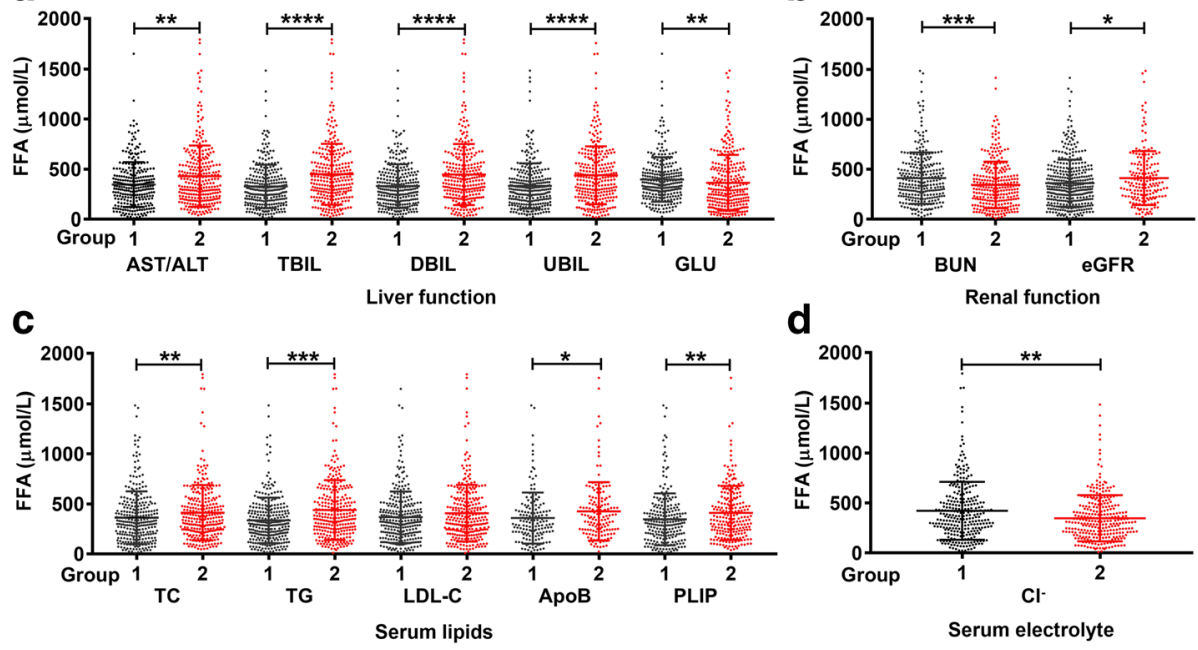

Fig. 3 The differences of serum FFAs between groups. a Liver function. b Renal function. c Serum lipids. d Serum electrolytes. Group- $1 \leq$ the median and Group-2 > the median. The median of each parameter was: AST/ALT, 1.38; TBIL, $8.6 \mu \mathrm{mol} / \mathrm{L} ; \mathrm{DBIL}, 1.5 \mu \mathrm{mol} / \mathrm{L} ; \mathrm{UBIL}, 7.05 \mu \mathrm{mol} / \mathrm{L} ; \mathrm{GLU}, 5.31 \mathrm{mmol} / \mathrm{L}$; BUN, $17.4 \mathrm{mmol} / \mathrm{L} ; \mathrm{TC}, 3.75 \mathrm{mmol} / \mathrm{L} ; \mathrm{TG}, 1.41 \mathrm{mmol} / \mathrm{L} ; \mathrm{LDL}-\mathrm{C}, 1.96 \mathrm{mmol} / \mathrm{L} ; \mathrm{ApoB}, 0.66 \mathrm{~g} / \mathrm{L} ; \mathrm{PLIP}, 2.04 \mathrm{mmol} / \mathrm{L} ; \mathrm{Cl}^{-}, 104.25 \mathrm{mmol} / \mathrm{L}$. The cutoff value for eGFR grouping is $15 \mathrm{~mL} / \mathrm{min} / 1.73 \mathrm{~m}^{2} .{ }^{*} P<0.05,{ }^{*} P<0.01{ }^{* *} P<0.001,{ }^{* * *} P<0.0001$. ALT, alanine transaminase; AST, aspartate aminotransferase; TBIL, total bilirubin; DBIL, direct bilirubin; UBIL, unconjugated bilirubin; GLU, glucose; BUN, blood urea nitrogen; eGFR, estimated glomerular filtration rate; TC, total cholesterol; TG, triglyceride; LDL-C, low-density lipoprotein cholesterol; ApoB, apolipoprotein B; PLIP, phospholipid

serum CREA ( $>1000 \mu \mathrm{mol} / \mathrm{L})$ for 4 months after he left hospital.

Notably, different individual FFAs had various effects on renal function. In most cells such as podocytes, the overload of saturated fatty acid could induce insulin resistance and cell death via lipid toxicity, whereas monounsaturated fatty acid could reverse this lipotoxicity [22]. Older individuals with a higher level of plasma polyunsaturated fatty acids were at lower risk of developing renal insufficiency [23]. CKD patients under hemodialytic treatment had an increase of monounsaturated fatty acids and a decrease of n-3 polyunsaturated fatty acids [18]. Earlier studies also observed that polyunsaturated fatty acids intake showed protective effects on renal function [3, 24].

Hyperglycemia was a risk factor for CKD [25]. In this study, serum GLU abnormally elevated in the rare case, similar results were also found in CRF patients with increased or reduced FFAs. Additionally, CRF patients with higher serum GLU and lower serum FFAs exhibited apparent reduction of eGFR (Additional file 1: Figure S1). Our data implied that, to some extent, serum lower FFAs and hyperglycemia promoted renal dysfunction in CRF patients.

Besides, the relation of population data between FFAs with AST/ALT, TBIL, DBIL and UBIL suggested normal liver function was vital for FFA metabolism. Serum FFAs depended on the balance between FFA release from adipose tissue and FFA uptake/oxidation by liver and muscle tissues [26]. In our study, FFA alterations were closely related to serum levels of TC, TG, LDL-C and ApoB, which were consistent with the source and metabolism of FFAs. In terms of serum electrolytes, we only found that $\mathrm{Cl}^{-}$was inversely correlated with FFAs. Interestingly, a recent study has proved that elevated FFAs and triacylglycerol levels directly reduced blood $\mathrm{Mg}^{2+}$ levels in metabolic disorders [27].

Nevertheless, this study could not rule out the limitations and challenges. Firstly, we only determined the mRNA expression of $L P L, H L$ and FASN in the case and 30 healthy males, these results should be further confirmed in a larger sample size study and covered more genes related to FFA metabolism. Secondly, owing to treatment requirements, the patients were not under standard diet, exercise and same medications, we therefore were unable to adjust for these factors in the statistical analyses. It is not surprising that all these limitations did not pose a serious problem to our findings that low FFAs indicated severe renal damages based on the large population data analysis.

\section{Conclusions}

Through clinical data analysis, literature review and gene expression of FFA-related metabolic enzymes, we concluded that the case with undetectable FFAs might be caused by proteinuria, $H L$ low expression, glucose and lipid metabolism disorders, and severe renal failure. More importantly, our study revealed the associations between serum FFAs and renal dysfunction, and highlighted the great clinical significance of monitoring serum lipids, especially FFAs, for CRF patients. 


\section{Additional file}

Additional file 1: Table S1. Primers used in this study for $\mathrm{QPCR}$. Table S2. The distributions of clinical parameters showing significant effects on serum FFAs. Figure S1. Serum FFAs and GLU exerted an opposite effect on renal function in CRF patients. (DOCX $105 \mathrm{~kb}$ )

\section{Abbreviations}

24 h-TP: 24-h urinary total protein; ALP: Alkaline phosphatase; ALT: Alanine transaminase; ApoA1: Apolipoprotein A1; ApoB: Apolipoprotein B; AST: Aspartate aminotransferase; BUN: Blood urea nitrogen; CKD: Chronic kidney disease; $\mathrm{CO}_{2}$ : Carbon dioxide; CREA: Creatinine; CRF: Chronic renal failure; DBIL: Direct bilirubin; DBP: Diastolic blood pressure; eGFR: Estimated glomerular filtration rate; FASN: Fatty acid synthase; FFAs: Free fatty acids; GFR: Glomerular filtration rate; GGT: Gamma-glutamyl transpeptidase; GLB: Globulin; GLU: Glucose; HDL-C: Highdensity lipoprotein cholesterol; HL: Hepatic lipase; IQR: Interquartile range; KDIGO: Kidney Disease: Improving Global Outcomes; LDL-C: Low-density lipoprotein cholesterol; Lp(a): Lipoprotein (a); LPL: Lipoprotein lipase; PLIP: Phospholipid; SBP: Systolic Blood Pressure; Scr: Serum creatinine; SD: Standard deviations; SOD: Superoxide dismutase; TBA: Total bile acid; TBIL: Total bilirubin: TC: Total cholesterol; TG: Triglyceride; TP: Total protein; UBIL: Unconjugated bilirubin

\section{Acknowledgments}

We are indebted to all the participants for their dedicated and conscientious collaboration. We also appreciate professor Wei Zhang (Department of Preventive Medicine, Northwestern University Feinberg School of Medicine, USA) for manuscript review.

\section{Authors' contributions}

All authors listed have made a substantial; direct and intellectual contribution to the work; and approved it for publication.

\section{Funding}

We thank the financial support from the National Natural Science Foundation of China $(81472023 ; 81772276)$ and Health Commission of Hubei Province Scientific Research Project (WJ2019H070; WJ2019H005).

\section{Availability of data and materials}

The datasets used and analyzed during the current study are available from the corresponding author on reasonable request.

\section{Ethics approval and consent to participate} Not applicable.

\section{Consent for publication}

Not applicable.

\section{Competing interests}

The authors declare that they have no competing interests

\section{Author details}

${ }^{1}$ Department of Clinical Laboratory, Center for Gene Diagnosis and Program of Clinical Laboratory, Zhongnan Hospital, Wuhan University, 169 Donghu Road, Wuhan 430071, Hubei Province, China. ${ }^{2}$ Department of Nephrology, Renmin Hospital of Huangmei County, Huanggang 435500, Hubei Province, China. ${ }^{3}$ Department of Nephrology, Zhongnan Hospital, Wuhan University, 169 Donghu Road, Wuhan 430071, Hubei Province, China.

Received: 16 May 2019 Accepted: 1 July 2019

Published online: 08 July 2019

\section{References}

1. Jha V, Garcia-Garcia G, Iseki K, Li Z, Naicker S, Plattner B, et al. Chronic kidney disease: global dimension and perspectives. Lancet. 2013;382(9888):260-72.

2. Angeli F, Gentile G, Trapasso M, Verdecchia P, Reboldi G. Role and prognostic value of individual ambulatory blood pressure components in chronic kidney disease. J Hum Hypertens. 2018;32(8-9):625-32.

3. Gopinath B, Harris DC, Flood VM, Burlutsky G, Mitchell P. Consumption of longchain n-3 PUFA, alpha-linolenic acid and fish is associated with the prevalence of chronic kidney disease. Br J Nutr. 2011;105(9):1361-8.
4. Hadden MJ, Advani A. Histone deacetylase inhibitors and diabetic kidney disease. Int J Mol Sci. 2018;19(9):2630.

5. Ng JK, Li PK. Chronic kidney disease epidemic: how do we deal with it? Nephrology. 2018:23(Suppl 4):116-20.

6. Libby AE, Wang H, Mittal R, Sungelo M, Potma E, Eckel RH. Lipoprotein lipase is an important modulator of lipid uptake and storage in hypothalamic neurons. Biochem Biophys Res Commun. 2015;465(2):287-92.

7. Cedo L, Santos D, Roglans N, Julve J, Pallares V, Rivas-Urbina A, et al. Human hepatic lipase overexpression in mice induces hepatic steatosis and obesity through promoting hepatic lipogenesis and white adipose tissue lipolysis and fatty acid uptake. PLoS One. 2017;12(12):e0189834.

8. Chong ETJ, Kuok SSE, Lee PC. Risk association, linkage disequilibrium and haplotype analyses of FASN rs4246445, rs2229425, rs2228305 and rs2229422 polymorphisms in overweight and obesity. Biolmpacts. 2018;8(3):159-65.

9. Sasaki H, Kamijo-kemori A, Sugaya T, Yamashita K, Yokoyama T, Koike J, et al. Urinary fatty acids and liver-type fatty acid binding protein in diabetic nephropathy. Nephron Clinical practice. 2009;112(3):c148-56.

10. Wahl P, Ducasa GM, Fornoni A. Systemic and renal lipids in kidney disease development and progression. Am J Physiol Renal Physiol. 2016;310(6):F433-45.

11. Bobulescu IA. Renal lipid metabolism and lipotoxicity. Curr Opin Nephrol Hypertens. 2010;19(4):393-402.

12. Attman PO, Samuelsson O, Alaupovic P. Lipoprotein metabolism and renal failure. Am J Kidney Dis. 1993;21(6):573-92.

13. Li SW, Wang J, Yang Y, Liu ZJ, Cheng L, Liu HY, et al. Polymorphisms in FADS1 and FADS2 alter plasma fatty acids and desaturase levels in type 2 diabetic patients with coronary artery disease. J Transl Med. 2016:14:79.

14. Guo SX, Yan YZ, Mu LT, Niu Q, He J, Liu JM, et al. Association of Serum Free Fatty Acids with hypertension and insulin resistance among rural Uyghur adults in far Western China. Int J Environ Res Public Health. 2015;12(6):6582-90.

15. Pasala S, Carmody JB. How to use... Serum creatinine, cystatin C and GFR. Arch Dis Child Educ Pract Ed. 2017:102(1):37-43.

16. White CA, Allen CM, Akbari A, Collier CP, Holland DC, Day AG, et al. Comparison of the new and traditional CKD-EPI GFR estimation equations with urinary inulin clearance: a study of equation performance. Clin Chim Acta. 2019:488:189-95.

17. Vienberg SG, Kleinridders A, Suzuki R, Kahn CR. Differential effects of angiopoietin-like 4 in brain and muscle on regulation of lipoprotein lipase activity. Mol metab. 2015;4(2):144-50.

18. Turolo S, Edefonti A, Syren ML, Marangoni F, Morello W, Agostoni C, et al. Fatty acids in nephrotic syndrome and chronic kidney disease. J Ren Nutr. 2018;28(3):145-55.

19. Wang H, Li H, Hou Z, Pan L, Shen X, Li G. Role of oxidative stress in elevated blood pressure induced by high free fatty acids. Hypertens Res. 2009:32(2):152-8.

20. Wei D, Ge M. The spatial distribution of BUN reference values of Chinese healthy adults: a cross-section study. Int J Biometeorol. 2018:62(12):2099-107.

21. Klooster A, Hofker HS, Navis G, Homan van der Heide JJ, Gans RO, van Goor $\mathrm{H}$, et al. Nonesterified fatty acids and development of graft failure in renal transplant recipients. Transplantation. 2013;95(11):1383-9.

22. Sieber J, Jehle AW. Free fatty acids and their metabolism affect function and survival of podocytes. Front Endocrinol. 2014;5:186.

23. Lauretani F, Semba RD, Bandinelli S, Miller ER 3rd, Ruggiero C, Cherubini A, et al. Plasma polyunsaturated fatty acids and the decline of renal function. Clin Chem. 2008;54(3):475-81.

24. Malhotra R, Cavanaugh KL, Blot WJ, Ikizler TA, Lipworth L, Kabagambe EK. Dietary polyunsaturated fatty acids and incidence of end-stage renal disease in the southern community cohort study. BMC Nephrol. 2016;17(1):152.

25. Yang L, Chu TK, Lian J, Lo CW, Lau PK, Nan H, et al. Risk factors of chronic kidney diseases in Chinese adults with type 2 diabetes. Sci Rep. 2018:8(1):14686.

26. Musutova M, Elkalaf M, Klubickova N, Koc M, Povysil S, Rambousek J, et al. The effect of hypoxia and metformin on fatty acid uptake, storage, and oxidation in L6 differentiated Myotubes. Front Endocrinol. 2018;9:616.

27. Kurstjens S, de Baaij JHF, Overmars-Bos C, van den Munckhof ICL, Garzero V de Vries MA, et al. Increased NEFA levels reduce blood $\mathrm{mg}(2+)$ in hypertriacylglycerolaemic states via direct binding of NEFA to $\mathrm{mg}(2)$. Diabetologia. 2019;62(2):311-21.

\section{Publisher's Note}

Springer Nature remains neutral with regard to jurisdictional claims in published maps and institutional affiliations. 